\title{
Ultrassonografia de modelos de sistemas deposicionais
}

\author{
Cássio Stein Moura ${ }^{1}$, Roseane M. Misságia ${ }^{2}$, Marco Ceia ${ }^{2}$
}

${ }^{1}$ Faculdade de Física, Pontifícia Universidade Católica do Rio Grande do Sul, Porto Alegre, RS, Brasil.

${ }^{2}$ Centro de Ciências e Tecnologias, Universidade Estadual do Norte Fluminense Darcy Ribeiro, Macaé, RJ, Brasil

Copyright 2014, SBGf - Sociedade Brasileira de Geofísica

Este texto foi preparado para a apresentação no VI Simpósio Brasileiro de Geofísica Porto Alegre, 14 a 16 de outubro de 2014. Seu conteúdo foi revisado pelo Comitế Técnico do VI SimBGf, mas não necessariamente representa a opinião da SBGf ou de seus associados. É proibida a reprodução total ou parcial deste material para propósitos comerciais sem prévia autorização da SBGf.

\section{Resumo}

Buscamos visualizar a estrutura interna de modelos de bancada utilizando um sistema industrial ultrassonográfico. Os sismogramas produzidos identificaram algumas feições sob investigação, mas apresentaram limitações na discriminação do objeto de interesse: a interface entre uma camada de carvão sobre uma camada de areia. Acreditamos que a baixa consolidação do material tenha intensificado o espalhamento Rayleigh da onda incidente levando a uma grande atenuação do sinal de retorno e à consequente dificuldade em discriminar as camadas. Propomos algumas formas de diminuir esse problema que incluem o aumento da consolidação do material ou do tamanho de grão dos sedimentos para reduzir os efeitos de espalhamento.

\section{Introdução}

O entendimento das correntes de turbidez possui grande interesse econômico. Devido à dificuldade de observação direta desses acontecimentos, busca-se reproduzir em escala reduzida o que acontece na natureza. Como os processos de simulação e sua interpretação são complicados, há a necessidade de grandes volumes de fluido e sedimentos, dificultando a implementação de um laboratório apropriado. Outro problema associado à técnica é a visualização das estruturas formadas que geralmente é limitada a sua topografia ou a cortes verticais da amostra que são invasivos e destrutivos.

Sistemas geológicos reais são rotineiramente analisados por ondas mecânicas de baixa frequência. Para modelos em pequena escala é necessário o uso de frequências elevadas, na faixa do ultrassom, para atingir o detalhamento desejado. Utilizamos um sistema ultrassonográfico que reproduz na pequena escala a técnica de levantamento sísmico em escala real.

\section{Metodologia}

Foram criados dois modelos sintéticos em caixas plásticas de tamanhos diferentes, cada um com 20 e 10 $\mathrm{cm}$ de largura, respectivamente. As caixas foram enchidas com água e, a seguir, areia fina foi despejada na parte inferior do depósito. A superfície da areia foi aplainada para garantir uma interface lisa. $O$ sistema foi deixado repousar por 1 hora para permitir a completa decantação da areia. Posteriormente, foi cuidadosamente despejado carvão cardiff sobre a areia. Num modelo, as camadas de areia e de carvão foram criadas com $4 \mathrm{~cm}$ de altura cada uma e no outro, com 1 e $2 \mathrm{~cm}$, respectivamente. As medidas foram feitas em duas configurações: i) o modelo com apenas uma fina lâmina d'água sobre a caixa plástica, sem água do lado de fora da caixa, e ii) o modelo colocado no interior de um tanque de vidro e imerso sob uma lâmina d'água de espessura variável, mas sempre maior do que a altura do modelo. A opção (ii) de usar um modelo menor do que o tanque com água permite que seja identificada a base de vidro do tanque nas regiões externas ao modelo, facilitando a interpretação da imagem sísmica. A Figura 1 mostra a aparência final do modelo imerso no tanque. Observe-se os transdutores posicionados no canto superior direito.

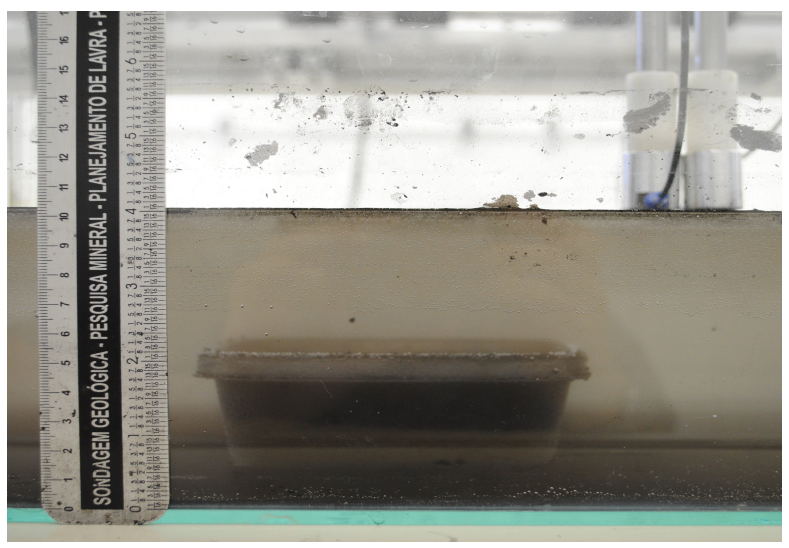

Figura 1- Modelo de depósito sob análise.

O equipamento de levantamento sísmico empregado encontra-se instalado no Laboratório de Modelagem Integrada de Reservatório do LENEP/UENF-Macaé, RJ. O Laboratório possui dois transdutores ultrassônicos de imersão que podem ser movimentados sobre uma linha horizontal. Eles são posicionados na orientação vertical, paralelos um ao outro e a distância entre eles pode ser alterada. Em no nosso experimento mantivemos os transdutores justapostos. Um transdutor faz o papel de emissor de sinal e o outro de receptor. Para mais detalhes sobre o equipamento, sugerimos o trabalho de Misságia et. al (2010). Os transdutores foram deslocados sobre uma linha horizontal na superfície da lâmina d'água, enquanto o sinal era emitido e captado pelos transdutores, com o objetivo de identificar a interface carvão/areia no interior do depósito. Foram utilizadas frequências de 250, 500 e 1000 kHz, tensões de excitação dos transdutores de 10 a $70 \mathrm{~V}$ e empilhamentos de 100 a 500 tiros por passo. Os 
transdutores foram mantidos em contato com a superfície da lâmina d'água para garantir o acoplamento acústico.

\section{Resultados}

Realizamos os primeiros testes com o modelo maior fora do tanque de vidro, ou seja, sem água a sua volta. Sobre a camada de areia foi criada uma lâmina d'água de $1 \mathrm{~cm}$. Os transdutores foram deslocados sobre uma linha reta entre as bordas internas da caixa contendo o modelo e foram utilizadas frequências de 250 e 500 kHz, com 100 tiros por passo. O sismograma permitiu a identificação da interface água/carvão, mas não conseguimos identificar a interface carvão/areia. Na Figura 2 mostramos o sismograma que foi obtido com a frequência de $250 \mathrm{kHz}$ e tensão de $10 \mathrm{~V}$ aplicada no transdutor e 100 tiros por passo. Não foi realizado nestes nenhum tipo de processamento numérico nesta aquisição.

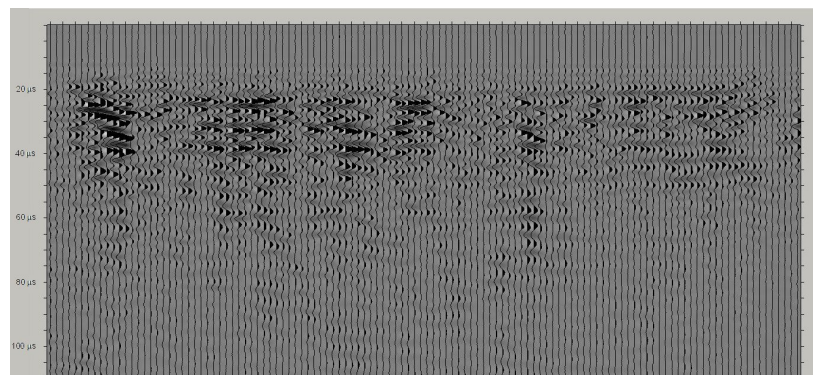

Figura 2 - Sismograma do modelo maior utilizando frequência de $250 \mathrm{kHz}$.

Diante da dificuldade de interpretação do sismograma, decidimos investigar o uso de marcadores junto ao modelo. Posicionamos o modelo em um tanque de vidro e o preenchemos com água até formar uma camada de 2 $\mathrm{cm}$ acima da superfície do carvão. Com esta nova geometria, os transdutores podiam se movimentar além da fronteira lateral do modelo. Desta forma, esperávamos identificar a superfície de vidro do fundo do tanque que poderia indicar a base do modelo composto pela interface areia/plástico. Do lado externo do modelo, posicionamos um marcador feito de um cilindro plástico preenchido com areia e de dimensões conhecidas $(4 \times 1 \mathrm{~cm})$ para servir de indicador de escala no sismograma. Obviamente, a escala provida pelo cilindro permite uma leitura direta apenas na parte externa ao modelo, que contém água pura, onde a velocidade do som é de $1.483 \mathrm{~m} / \mathrm{s}$ (Nussenzveig, 2002). No interior do modelo, deve-se converter a escala levando-se em conta a velocidade de propagação do som no meio. Segundo Tono (2007), a velocidade de propagação do som no pó de carvão molhado é de $1.834 \mathrm{~m} / \mathrm{s}$, não importando a concentração de água em relação ao carbono. Levando essa velocidade em consideração, podemos calcular a posição no sismograma em que deveria se encontrar a interface carvão/areia. Na Figura 3, mostramos o sismograma do modelo quando colocado no interior do tanque com nível de água acima da caixa plástica e o cilindro de plástico servindo de escala no lado externo da caixa. Nesta varredura foram utilizados 200 tiros por passo, frequência de $500 \mathrm{kHz}$ e tensão de $10 \mathrm{~V}$ aplicados ao transdutor.

O movimento dos transdutores iniciou no lado esquerdo da figura e terminou no lado direito. Na parte inicial do movimento (esquerda), pode-se identificar nitidamente o fundo do tanque de vidro e o topo do cilindro de plástico. Indo para a direita, o transdutor passa pelo marcador, o qual pode ser nitidamente observado no sismograma, e chega à parede de plástico do modelo. Nesse ponto, hipérboles de difração podem ser observadas. A seguir, quando o transdutor percorre a região acima do modelo, pode-se ver a superfície do carvão em contato com a água. Entretanto, a estrutura interna do modelo (interface carvão/areia) não aparece de forma clara. Os transdutores continuam, assim, o seu movimento adiante e ultrapassam a borda direita do modelo, mas esta parte do sismograma não é mostrada na figura pois ela é equivalente à parte do lado esquerdo. A posição calculada para a interface carvão/areia é mostrada na Figura 3 pela linha branca horizontal, mas não conseguimos encontrar nenhum refletor de maneira nítida a essa profundidade. A superfície inferior do modelo representada pela interface areia/plástico também não foi identificada.

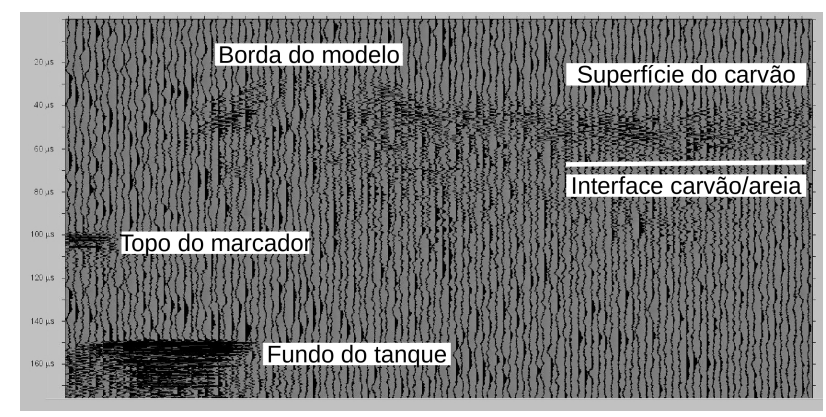

Figura 3 - Sismograma do modelo maior imerso no tanque com água, utilizando frequência de $500 \mathrm{kHz}$.

Para reduzir o efeito do processo de atenuação do sinal pelo carvão, decidimos estreitar a espessura da camada de carvão do modelo. Construímos o modelo menor , em que a camada de carvão tem apenas $2 \mathrm{~cm}$ de espessura, e o colocamos no interior do tanque seco. Água foi colocada lentamente no interior do tanque até cobrir totalmente o modelo e formar uma lâmina de $2 \mathrm{~cm}$ acima da superfície do carvão. Também optamos por aumentar a tensão aplicada no transdutor para $50 \mathrm{~V}$, a fim de obter um sinal mais intenso e uma melhora na razão sinal/ruído.

$\mathrm{Na}$ Figura 4 é mostrado o sismograma resultante utilizando empilhamento de 500 tiros por passo, frequência de $500 \mathrm{kHz}$ e tensão de $50 \mathrm{~V}$ aplicados ao transdutor. Algumas das estruturas que já foram observadas no modelo maior se repetem, tais como a reflexão no fundo do tanque na parte externa ao modelo, a difração da onda sonora nas bordas do modelo e a reflexão na superfície do carvão. Além destes eventos, 
surgiram novas linhas horizontais que, à primeira vista, poderiam parecer devidas à reflexão na interface carvão/areia, afinal, estão numa posição acima (tempo de trânsito menor) do que a superfície do tanque na parte externa do modelo. Essas novas linhas poderiam ser também devidas às reflexões no fundo do modelo nas interfaces areia/plástico ou plástico/vidro. Essa suposição seria razoável, pois as novas linhas horizontais possuem um tempo de trânsito menor do que as linhas na parte externa do modelo. Isso condiz com o fato de a onda sonora viajar mais rápido no carvão e na areia do que na água. Porém, surgiram também algumas linhas menos intensas em posições abaixo da superfície inferior do tanque. Suspeitamos, então, que as novas linhas horizontais pudessem ser artefatos de reverberação. Apoiando essa desconfiança estão as hipérboles de menor intensidade representando a difração da onda incidente nas bordas do modelo, que parecem ser reproduzidas em várias posições empilhadas, inclusive abaixo da base do tanque. Para identificar a presença de artefatos de reverberação, aumentamos a espessura da camada de água sobre o modelo e observarmos que a variação no tempo de trânsito do sinal duplamente refletido também aumenta, conforme a Figura 5. Pode-se observar nitidamente que a segunda camada de linhas de reflexão deslocou-se para uma posição mais abaixo, evidenciando o fato de elas na verdade serem apenas um artefato de reflexão e não o sinal proveniente de uma estrutura refletora real. Assim, comparando-se as Figuras 4 e 5 , é fácil observar que na Figura 4 existem dois artefatos de reflexão, enquanto que na Figura 5 apenas o $1^{\circ}$ artefato é visto de forma clara e em um nível mais profundo que na imagem anterior.

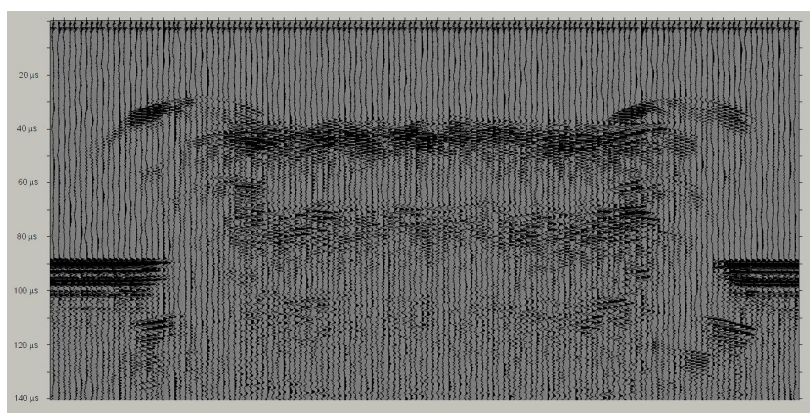

Figura 4 - Sismograma do modelo menor imerso no tanque com água, utilizando frequência de $500 \mathrm{kHz}$.

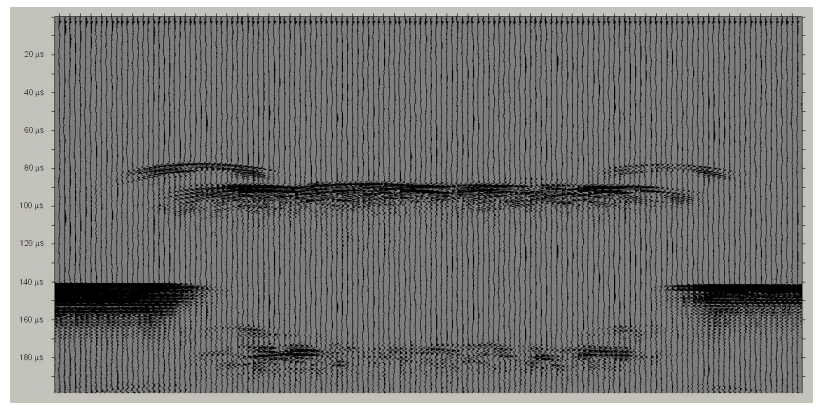

Figura 5 - Sismograma do modelo menor após o aumento da lâmina d'água.
Existem ainda algumas diferenças menores entre as Figuras 4 e 5 . $O$ aumento da lâmina d'água desloca 0 tempo de trânsito correspondente à reflexão na superfície do carvão de $38 \mu$ s para $87 \mu$ s condizendo com a maior profundidade do modelo. A Figura 4 apresenta uma quantidade maior de detalhes do que a Figura 5, porque empilhamos 500 tiros por passo naquela em comparação com 200 tiros por passo na última, de forma que, nesta, a razão sinal/ruído é menor. Infelizmente, a interface carvão/areia não foi identificada em nenhum dos dois casos, mas apenas uma região difusa de espalhamentos. Fizemos ainda tentativas nas frequências de 100, 250 e $1000 \mathrm{kHz}$, mas a resposta do sistema foi similar. O aumento da tensão até o valor máximo possível pelo equipamento $(70 \mathrm{~V})$ também não mostrou melhoras na separação das camadas no sismograma.

\section{Discussão e Conclusões}

Fizemos várias tentativas de identificar uma interface refletora carvão/areia em um modelo de bancada. Foram testadas frequências na faixa de centenas de $\mathrm{kHz}$, empilhamento de centenas de tiros/passo e tensões no transdutor de algumas dezenas de volts. Estruturas de materiais compactados puderam ser detectadas tais como as bordas da caixa plástica do modelo e o fundo do tanque na região externa do modelo, com posicionamento de acordo com o cálculo que leva em conta a velocidade de propagação da onda no meio. No entanto, não conseguimos identificar o sinal da interface de interesse (carvão/areia), mesmo diminuindo a espessura da camada superior pela metade. Também não foi possível visualizar o fundo do tanque na região abaixo da amostra. Ele mostrou-se visível apenas nas partes externas à amostra. A falta de visualização do fundo indica que o sinal ultrassônico ou não esteja chegando até o fundo do sistema ou não esteja conseguindo retornar à superfície e, por conseguinte, ao transdutor receptor. Ou seja, está ocorrendo uma atenuação muito intensa do sinal.

A técnica ecográfica costuma assumir uma reflexão especular do sinal nas descontinuidades de impedância acústica para produzir uma imagem da estrutura. Isso ocorre quando a superfície é suave e, como consequência, valem as mesmas leis da reflexão e refração que são aplicadas aos raios de luz. No entanto, quando a superfície é rugosa, ou seja, possui ondulações com dimensões próximas ao comprimento de onda do feixe incidente, o feixe refletido pode ser espalhado em vários ângulos, diminuindo a intensidade do sinal detectado no retorno. Durante a preparação da amostra, tomamos o cuidado para que a superfície da camada de areia fosse o mais plana possível, justamente para evitar esse tipo de efeito. Porém, na técnica ultrassonográfica, quando o som encontra uma estrutura cuja dimensão é muito menor do que seu comprimento de onda, ele é irradiado pela estrutura em todas as direções de forma praticamente isotrópica (Farr e Alissy-Roberts, 1998). Nesse caso, apenas uma parcela muito pequena do sinal inicial retorna ao receptor e sua intensidade diminui com o quadrado da profundidade. O espalhamento da onda incidente por partículas muito menores que o comprimento de onda incidente é conhecido por espalhamento de Rayleigh e, por exemplo, explica a cor 
azul da atmosfera terrestre. A teoria para ondas eletromagnéticas pode ser adaptada para explicar 0 espalhamento de ondas mecânicas.

Considerando as frequências que utilizamos neste trabalho e a velocidade do som no meio, podemos facilmente calcular o comprimento de onda empregado: entre 1,8 e 7,3 mm. O tamanho médio do grão de carvão utilizado foi da ordem de $0,05 \mathrm{~mm}$. Comparando-se os valores e observando a grande razão entre eles, é razoável assumir que o espalhamento esteja exercendo um papel importante no experimento. Na preparação da amostra, os materiais areia e carvão foram apenas despejados no interior do recipiente, sem sofrer nenhuma forma de compactação extra, levando a um estado de baixa consolidação. Isso pode ter evidenciado o efeito de espalhamento. Se, por outro lado, o material tivesse sido altamente compactado, como ocorre em rochas sedimentares, os grãos de carvão sofreriam um aglomeramento e seu tamanho efetivo seria maior, podendo chegar a dimensões superiores ao do comprimento de onda do feixe incidente. Neste caso, acreditamos que 0 espalhamento Rayleigh seria diminuído, evidenciando a reflexão especular nas descontinuidades de impedância acústica.

Esta tentativa inicial de visualização da estrutura interna de depósitos via ultrassonografia indicou a necessidade de alterações no sistema de medidas e preparação de amostras que deverão ser implementadas em futuros trabalhos. Uma possibilidade é a utilização de um modelo com uma compactação maior, equivalente a um longo período de decantação do sistema ou mesmo uma pressão externa aplicada, para simular o processo de litificação de sedimentos. Para aumentar a consolidação, os modelos empregados neste trabalho foram deixados repousando para serem analisados mais tarde. Será feito um acompanhamento em intervalos de tempo regulares para observar a evolução da compactação.

Um modelo que tenha sido drenado e seco com espessura da ordem do metro (espessura típica em sedimentos produzidos em grandes laboratórios de simulação física) deve apresentar uma compactação maior, o que diminuiria o espalhamento do sinal. Porém, apesar dessa possibilidade aparentemente melhorar a visualização, a configuração coloidal obtida em tanques de simulação não é conservada na etapa de drenagem, descaracterizando o processo de sedimentação.

Enfim, existe, ainda, a possibilidade de trocar a substância de simulação, escolhendo alguma que apresente uma melhor compactação ou um tamanho de grão maior do que o comprimento de onda incidente, ao mesmo tempo que mantenha propriedades hidráulicas similares às dos materiais empregados em simulações. Este caminho requer um profundo estudo na área de síntese de novos materiais.

\section{Agradecimentos}

Os autores agradecem à Petrobras pelo auxílio financeiro dispendido neste trabalho de investigação e pela permissão de publicação dos resultados.

\section{Referências}

FARR RF, ALLISY-ROBERTS PJ. 1998. Physics for Medical Imaging. Saunders: London, p.196.

MISSÁGIA RM, CEIA M, PESSANHA CA. 2010. Modelagem Física Sísmica na UENF/LENEP: descrição e teste do sistema. In: IV Simpósio Brasileiro da SBGf, 2010, Brasília. Anais. Brasília: SBGf, 2010. CD-ROM.

NUSSENZVEIG, HM. 2002. Curso de Física Básica, v. 2, Edggard Blücher, São Paulo, 314 p.

TONO, H. 2007. Phantom Seismic Stratigraphy: The origins of time-line reflectors and missing base-level markers from images and properties of experimental strata. Tese (Doctor of Philosophy) Earth and Ocean Sciences Department, Nicholas School of the Environment, Duke University, 2007. 119 p. 